\title{
A Comparative Study of Inclusion Complexes of Orthosubstituted [Arylidenamino]-1,3,4- thiadiazino[6,5b] Indole Derivatives
}

\author{
SUNAKAR PANDA AND JAGAT KRUSHNA TRIPATHY \\ P.G. Department of Chemistry \\ Berhampur University, Bhanja Bihar, Odisha \\ Sunakar_bu@yahoo.co.in \\ Jagat_luna_tripathy@yahoo.com
}

Received 09 August 2011; Accepted 04 October 2011

\begin{abstract}
Some[Arylidenamino]-1,3,4-thiadiazino[6,5b] indoles have been synthesized starting from indole-2,3-dione, thiosemicarbazide and aromatic aldehydes with activating and deactivating groups. Inclusion complexes of these compounds have been prepared with $\beta$-cyclodextrin so as increase the solubility and bioaccessibility. Thermodynamic properties like change in free energy, change in enthalpy, change in entropy and stability constant of the inclusion complexes have been determined to know whether the inclusion complex formation is thermodynamically allowed or not. The compounds and their inclusion complexes are also screened againt S.aureus and E.coli.to know the antibacterial activity change after inclusion complex formation The antioxidant activities are also studied.
\end{abstract}

Key Words: Substituted indoles, $\beta$-Cyclodextrin, Inclusion complex, antimicrobial activity,antioxidant activity.

\section{Introduction}

Today bacterial resistance to antibiotics is a big challenge for mankind. A number of drugs is no way helpful for the humanbody which had a wonderful effect for chronic and common diseases. Indole and its derivatives are very good pharmacophores exhibiting wide spectrum of pharmacological activities such as antidepressive, anti-inflammatory, anti-fungicidial, anti-bactericidial and anti-tuberculostatic activities ${ }^{1-4}$. Azediones and thiazolidinones show excellent antimicrobial activities ${ }^{5-8}$. There are also reports that compounds containing indole or substituted indole coupled with azedinone or thiazolidinone units are acting as drugs for treating a number of diseases ${ }^{7,8}$. Since the bio-accessibility of drugs depend upon their solubility, the poor solubility of these compounds in aqueous medium may be a limiting factor reducing pharmacological activities. The solubility and bio-accessibility of these compounds can be enhanced significantly by forming inclusion complex with cyclodextrins ${ }^{9}$.Out of all the known cyclodextrins, $\beta$-cyclodextrin is usually considered for 
inclusion complex formation because it is cheaper, easily available and highly stable towards heat and oxidation ${ }^{10-12}$.

In the present work an attempt has been made to synthesize some 2-[arylidenamino]1,3,4-thiadiazino[6,5b]indoles in their purest forms starting from indole-2,3-dione. The aryl aldehydes considered in the synthesis are of three types containing hydroxyl and chloro group at ortho position. The inclusion complexes of the compounds have been prepared with $\beta$-cyclodextrin. The formation of compounds and their inclusion complexes have been ascertained from elemental analysis, melting point data and study of spectral characteristics. Thermodynamics properties of the inclusion complexes are also studied to know thermodynamic stability of inclusion complexes and the type of interaction in between the host and guest.

\section{Experimental}

\section{Apparatus and Materials}

All the chemicals of acceptable standards were procured from local market. Double distilled water to be used as solvent was prepared in the laboratory. Electronic spectra were recorded on Shimadzu UV-1700 Spectrophotometer and IR spectra were recorded in KBr pellets in Shimadzu 8400 FTIR Spectrophotometer. Melting points were recorded by open capillary method.

Synthesis of 2-[Arylidenamino]-1, 3, 4-thiadiazino [6,5b] indoles

Three different 2-[arylidenamino]-1, 3, 4-thiadiazino [6,5b] indoles were synthesized starting from indole -2,3--dione (as per the scheme-I) through the following intermediate steps $^{8}$.

i) Synthesis of 3-Thiosemicarbazideindole-2-one : A mixture of $2 \mathrm{gm}$ of indole-2, 3-dione and $1.23 \mathrm{gm}$ of thiosemicarbazide in $50 \mathrm{ml}$ of methanol was refluxed for one hour. The completion of the reaction was checked by TLC. The excess of methanol was distilled out. The content was cooled and poured into ice cold water. It was filtered, washed with water, dried and recrystallised from ethanol to obtain 3-Thiosemicarbazideindole-2-one

ii) Synthesis of 2-Amino-1, 3, 4-thiadiazino [6, 5-b] indole: $3 \mathrm{gm}$ of

3-Thiosemicarbazideindole-2-one was mixed with small quantity of cold and concentrated $\mathrm{H}_{2} \mathrm{SO}_{4}$. The reaction mixture was left at room temperature for 16 hours. The reaction mixture was then poured into ice-cold water and neutralized with liquid $\mathrm{NH}_{3}$ to obtain a solid mass. The solid mass was filtered by using Whatmann-42 filter paper. It was washed with water, dried and recrystallised from ethanol to yield 2-Amino-1, 3, 4-thiadiazino [6, 5b] indole.

a) Synthesis of Benzylidenamino-1, 3, 4-thiadiazino [6,5b] indole (Compound-I): 1.06gm of Benzaldehyde and $2.02 \mathrm{gm}$ of 2-Amino-1, 3, 4-thiadiazino [6, 5-b] indole were taken in $50 \mathrm{ml}$ of methanol. The mixture was refluxed for 6 hours in presence of glacial acetic acid. The completion of the reaction was checked by TLC and excess of methanol was distilled off. The refluxed mixture was poured into ice-cold water, filtered, washed with water and dried.

b) Synthesis of 2-[2-hydroxy benzylidenamino]-1, 3, 4-thiadiazino [6,5b] indole (Compound-II) 1.22 gm of o-hydroxybenzaldehyde and 2.02gm of 2-Amino-1, 3, 4thiadiazino $[6,5-\mathrm{b}]$ indole were taken in $50 \mathrm{ml}$ of methanol. The mixture was refluxed for 6 hours in presence of glacial acetic acid. The completion of the reaction was checked by TLC and excess of methanol was distilled off. The refluxed mixture was poured into ice-cold water, filtered and washed with water and dried. The dried mass was crystallized from ethanol. 
Scheme-I<smiles>NC(N)=S</smiles><smiles>C=CC=C1C(O)=Nc2ccccc21</smiles>

Cold Conc. $\mathrm{H}_{2} \mathrm{SO}_{4}$<smiles>Nc1nnc2c3ccccc3nc-2s1</smiles><smiles>[R]c1cccc(C=C(C)C(=O)O)c1</smiles><smiles>[R]CCCCCC=Nc1nnc2c3ccccc3nc-2s1</smiles>

$\mathrm{R}=\mathrm{H}, \mathrm{o}-\mathrm{OH}$ and $\mathrm{o}-\mathrm{Cl}$. 
c) Synthesis of 2-[2-chloro benzylidenamino]-1, 3, 4-thiadiazino [6,5b] indole (Compound-II) :1.465 gm of o-chlorobenzaldehyde and 2.02gm of 2-Amino-1, 3, 4thiadiazino $[6,5-\mathrm{b}]$ indole were taken in $50 \mathrm{ml}$ of methanol. The mixture was refluxed for 6 hours in presence of glacial acetic acid. The completion of the reaction was checked by TLC and excess of methanol was distilled off. The refluxed mixture was poured into ice-cold water, filtered and washed with water and dried. The dried mass was crystallized from ethanol.

\section{Phase Solubility Measurements:-}

The aqueous phase solubility of the compound at various concentration. $\beta$-cyclodextrin ( 0 $10 \mathrm{mMl}$ ) was studied by Higuchi-Corner method ${ }^{13}$. Accurately weighed sample of these compounds was shaken in rotary flash shaker at room temperature in a series of conical flask for a period of 48 hours till the attainment of equilibrium. The solutions were filtered through whatmann-42 filter paper and were analyzed in a UV-visible spectrophotometer. The various values of absorbance at $\lambda$-max were plotted against different concentrations of $\beta$ -cyclodextrin. The dried mass was recrystallized from ethanol.

\section{Synthesis of inclusion complexes:-}

The inclusion complexes of the compounds (I,II and III) with $\beta$-cyclodextrin were prepared as per co-precipitation method ${ }^{14}$. The solutions of these compounds in required concentrations were added drop by drop to $\beta$-cyclodextrin solution of the required concentration. The mixtures were stirred for a period of 48 hours and filtered. The filtrate was cooled for 24 hours in refrigerators. The precipitate obtained was filtered through G-4 crucible, washed with water and dried in air for 24 hours.

\section{Study of thermodynamic properties:-}

The thermodynamic stability constant of the complexes was calculated using BenesiHilderband relation ${ }^{15}$. The stability constant $\mathrm{K}$ of each complex was calculated with increasing temperature. From the slope of the linear plot of $\operatorname{lnK}$ vs. $1 / \mathrm{T}, \Delta \mathrm{H}$ was calculated. Then $\Delta \mathrm{S}$ was calculated from vant Hoff's equation

$$
\ln \mathrm{K}=\Delta \mathrm{H} / \mathrm{RT}-\Delta \mathrm{S} / \mathrm{R}
$$

The value of $\Delta \mathrm{G}$ was calculated at $298 \mathrm{~K}$ using the equation:

$$
\Delta \mathrm{G}=-\mathrm{RT} \ln \mathrm{K}
$$

\section{Antibacterial study}

The antibacterial activity of compounds is studied as per cup-plate methode..The solutions of the test compounds were prepared in dimethylsulfoxide (DMSO) at $500 \mu \mathrm{g} / \mathrm{ml}$. The bacterial strains are inoculated into $100 \mathrm{ml}$ of the sterile nutrient broth and incubated at $37 \pm 1$ ${ }^{\circ} \mathrm{C}$ for 24 hours. The density of the bacterial suspension is standardized by McFarland method. Well of uniform diameter $(6 \mathrm{~mm})$ are made on agar plates, after inoculating them separately with the test organisms aseptically. The drug, control and the test compounds are introduced with the help of micropipette and the plates are placed in the refrigerator at 8 $10^{\circ} \mathrm{C}$ for proper diffusion of drug into the media. After two hours of cold incubation, the petriplates are transferred to incubator and maintained at $37 \pm 2^{\circ} \mathrm{C}$ for $18-24$ hours. Then the petriplates are observed for zone of inhibition by using vernier scale. The results are reported by comparing the zone of inhibition shown by the test compounds with standard 
drug Tetracycline. The results are the mean value of zone of inhibition of three sets measured in millimeter ${ }^{25}$.

\section{Evaluation of Antioxidant activity}

In the present study DPPH scavenging assay method was used for screening the antioxidant activity of the synthesized compounds. The antioxidant activity using the DPPH assay was assessed by the method of Tagashira and Ohtake. Test sample solution was prepared in $100 \mu \mathrm{g} / \mathrm{ml}$ concentration in ethanolic DPPH. After vortexing, the mixture was incubated for 10 minutes at room temperature and the absorbance at $517 \mathrm{~nm}$ was measured. The difference in absorbance between a test sample and a control was considered as activity. BHT was used as reference substance ${ }^{27}$.

\section{Results and Discussion}

The synthesis of Compound-I (Benzylidenamino-1,3,4-thiadiazino[6,5b]indole), CompoundII : 2-[2- Hydroxy Benzylidenamino]-1,3,4-thiadiazino[6,5b]indole Compound-III : 2-[2-Chloro Benzylidenamino]-1,3,4-thiadiazino[6,5b]indole have been confirmed from elemental analysis and IR data as shown in Table-1. The elemental composition matches with theoretical data IR data of the compound-I show characteristic absorption at $672,1296,1611,1682$ and $3141 \mathrm{~cm}^{-1}$ indicating the presence of C-S, C-C ,N-N, C=N and benzene ring in the compound as expected. IR-data of the compound -II show characteristic absorptions at $672,1294,1611,1683$ and $3142 \mathrm{~cm}^{-1}$ indicating the presence of C-S, C-C,N-N, $\mathrm{C}=\mathrm{N}$ and benzene ring in the compound as expected. Similarly, the IR-data of the compound -III show characteristic absorptions at $674,1371,1462,1595,1674$ and $3265 \mathrm{~cm}^{-1}$ indicating the presence of C-S, C-C , C-N, N-N, C=N and benzene ring in the compound. IR data of the complex-I show characteristic absorption at $670,1290,1605,1679$ and $3130 \mathrm{~cm}^{-1}$ indicating the presence of $\mathrm{C}-\mathrm{S}, \mathrm{C}-\mathrm{C}, \mathrm{N}-\mathrm{N}, \mathrm{C}=\mathrm{N}$ and benzene ring in the compound as expected. IR-data of the complex -II show characteristic absorptions at 669,1290,1610,1679 and $3130 \mathrm{~cm}^{-1}$ indicating the presence of $\mathrm{C}-\mathrm{S}, \mathrm{C}-\mathrm{C}, \mathrm{N}-\mathrm{N}, \mathrm{C}=\mathrm{N}$ and benzene ring in the compound as expected. Similarly, the IR-data of the complex -III show characteristic absorptions at 672 , $1370,1460,1594,1672$ and $3262 \mathrm{~cm}^{-1}$ indicating the presence of C-S, C-C ,C-N, N-N, C=N and benzene ring in the compound.

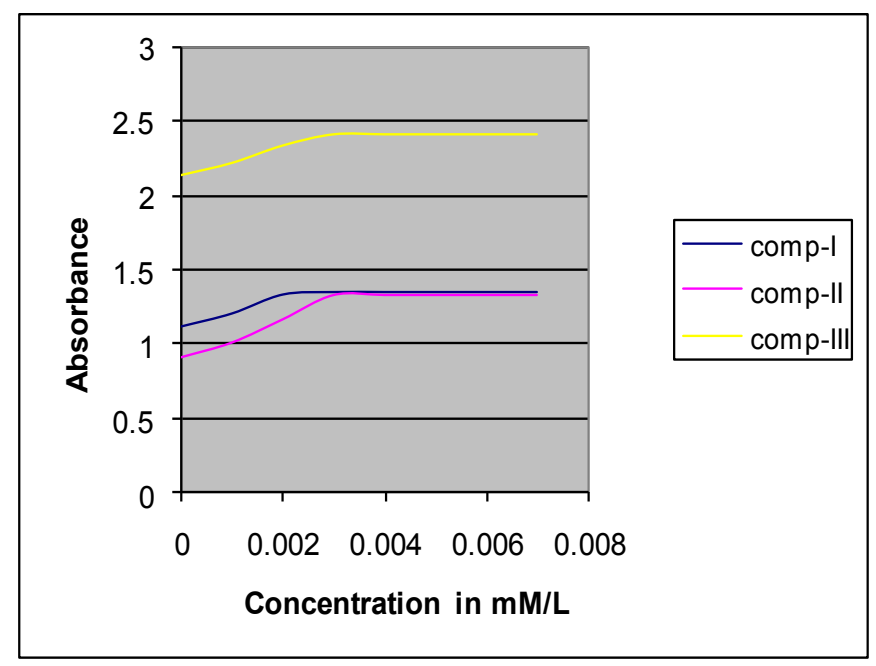

Figure 1: Phase solubility plot of Compound I, II and III. 
Table 1: Analytical data of Compounds with and without inclusion complex.

Compound-I : Benzylidenamino-1,3,4-thiadiazino[6,5b]indole.

Compound-II : 2-[2- Hydroxy Benzylidenamino]-1,3,4-thiadiazino[6,5b]indole.

Compound-III : 2-[2--Chloro Benzylidenamino]-1,3,4-thiadiazino[6,5b]indole.

\begin{tabular}{|c|c|c|c|c|c|c|c|c|c|c|}
\hline Sl.No. & $\begin{array}{l}\text { Compound/ } \\
\text { Complex }\end{array}$ & $\begin{array}{l}\text { Melting } \\
\text { Point }\end{array}$ & Colour & \multicolumn{5}{|c|}{$\begin{array}{l}\text { Elemental Analysis } \\
\text { (First line indicates finding value \& } \\
\text { second line indicates calculated value } \\
\text { ) }\end{array}$} & $\begin{array}{l}\lambda \\
\max \\
\left(\mathrm{A}^{0}\right)\end{array}$ & $\begin{array}{l}\mathrm{IR}(\mathrm{KBr}) \\
\mathrm{cm}^{-1}\end{array}$ \\
\hline 1 & $\begin{array}{l}\text { Compound- } \\
\text { I }\end{array}$ & 224 & Yellow & $\begin{array}{l}\mathrm{C} \\
66.4 \\
66.2\end{array}$ & $\begin{array}{l}\mathrm{H} \\
3.45 \\
3.44\end{array}$ & $\begin{array}{l}\mathrm{N} \\
19.4 \\
19.3\end{array}$ & $\begin{array}{l}\mathrm{S} \\
1.0 \\
1.03\end{array}$ & $\mathrm{O}$ & 3550 & $\begin{array}{l}\text { 672(C-S) } \\
1296(\mathrm{C}-\mathrm{C}) \\
1611(\mathrm{~N}-\mathrm{N}) \\
1682(- \\
\mathrm{C}=\mathrm{N}) \\
3141 \text { (Ring) }\end{array}$ \\
\hline 2 & $\begin{array}{l}\text { Compound- } \\
\text { I- } \beta-C D\end{array}$ & 228 & $\begin{array}{l}\text { Pale } \\
\text { Yellow }\end{array}$ & - & - & - & - & - & 3542 & $\begin{array}{l}670(\mathrm{C}-\mathrm{S}) \\
1290(\mathrm{C}-\mathrm{C}) \\
1605(\mathrm{~N}-\mathrm{N}) \\
1679(\mathrm{C}=\mathrm{N}) \\
\text { 3130()Ring })\end{array}$ \\
\hline 3 & $\begin{array}{l}\text { Compound- } \\
\text { II }\end{array}$ & 239 & Yellow & $\begin{array}{l}62.8 \\
62.75\end{array}$ & $\begin{array}{l}3.3 \\
3.27\end{array}$ & $\begin{array}{r}18.4 \\
18.3\end{array}$ & $\begin{array}{l}10.5 \\
10.46\end{array}$ & $\begin{array}{l}5.0 \\
5.23\end{array}$ & 3540 & $\begin{array}{l}672(\mathrm{C}-\mathrm{S}) \\
1294(\mathrm{C}-\mathrm{C}) \\
1611(\mathrm{~N}-\mathrm{N}) \\
1683(- \\
\mathrm{C}=\mathrm{N}) \\
3142 \text { (Ring) }\end{array}$ \\
\hline 4 & $\begin{array}{l}\text { Compound- } \\
\text { II- } \beta-C D\end{array}$ & 246 & $\begin{array}{l}\text { Pale } \\
\text { Yellow }\end{array}$ & - & - & - & - & - & 3530 & $\begin{array}{l}669(\mathrm{C}-\mathrm{S}) \\
1290(\mathrm{C}-\mathrm{C}) \\
1610(\mathrm{~N}-\mathrm{N}) \\
1679(- \\
\mathrm{C}=\mathrm{N}) \\
3130 \text { (Ring) }\end{array}$ \\
\hline 5 & $\begin{array}{l}\text { Compound- } \\
\text { III }\end{array}$ & 243 & Yellow & $\begin{array}{l}59.0 \\
59.16\end{array}$ & $\begin{array}{l}2.61 \\
2.77\end{array}$ & $\begin{array}{l}17.2 \\
17.3\end{array}$ & $\begin{array}{l}9.0 \\
9.86\end{array}$ & & 3536 & $\begin{array}{l}674(\mathrm{C}-\mathrm{S}) \\
1371(\mathrm{C}-\mathrm{C}) \\
1462(\mathrm{C}-\mathrm{N}) \\
1595(\mathrm{~N}-\mathrm{N}) \\
1674(- \\
\mathrm{C}=\mathrm{N}) \\
3265(\text { Ring })\end{array}$ \\
\hline 6 & $\begin{array}{l}\text { Compound- } \\
\text { III - } \beta-C D\end{array}$ & 248 & Yellow & - & - & - & - & - & 3528 & $\begin{array}{l}672(\mathrm{C}-\mathrm{S}) \\
1370(\mathrm{C}-\mathrm{C}) \\
1460(\mathrm{C}-\mathrm{N}) \\
1594(\mathrm{~N}-\mathrm{N}) \\
1672(- \\
\mathrm{C}=\mathrm{N}) \\
3262(\text { Ring) }\end{array}$ \\
\hline
\end{tabular}

The synthesis of inclusion complexes of compound I (Benzylidenamino-1,3,4thiadiazino[6,5b] indole) Compound-II: 2-[2- Hydroxy Benzylidenamino]-1,3,4thiadiazino[6,5b] indole Compound-III: 2-[2--Chloro Benzylidenamino]-1,3,4thiadiazino[6,5b] indole were confirmed from changes in melting point, colour and spectral characteristics (UV-Vis and IR). The melting point of compound I, II and III are found to be $\mathrm{s} 224^{\circ} \mathrm{C}, 239^{\circ} \mathrm{C}$ and $243^{\circ} \mathrm{C}$ but their inclusion complexes have melting points $228^{\circ} \mathrm{C}, 246^{\circ} \mathrm{C}$ and $248^{\circ} \mathrm{C}$ (Table-1). The colour of the compound I, II and III are found to be yellow but their inclusion complexes have colours pale yellow, pale yellow and yellow respectively. 
The absorption maximum of the compounds I, II and III are found at 3550, 3540 and 3536 $\mathrm{A}^{\mathrm{o}}$ but their but their inclusion complexes have absorption maximum at 3542,3530 and 3528 $\mathrm{A}^{\mathrm{o}}$. The higher melting point of inclusion complexes than the compounds is due to the fact that extra amount of thermal energy is required for the latter to bring it out of $\beta$ cyclodextrin cavity.

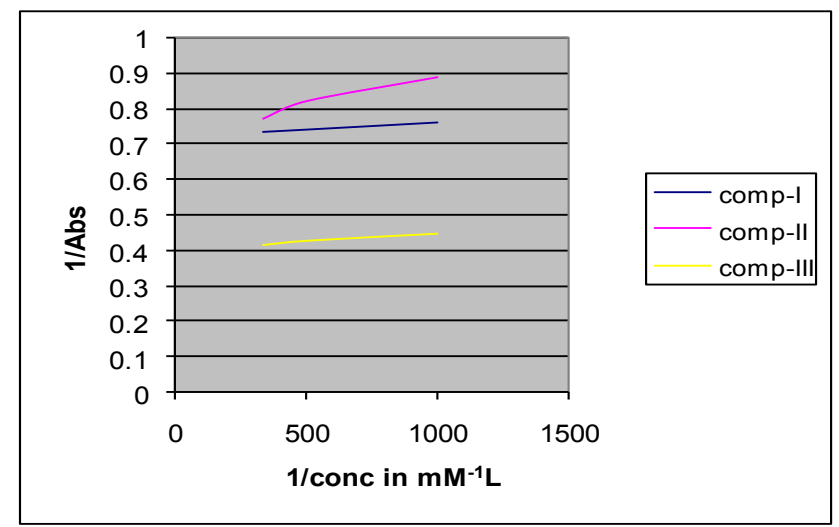

Figure 2: Plot of 1/ O.D. vs. Conc. of Compound I, II and III.

It is quite interesting to note that the absorption maxima undergo a shift towards lower wavelength after the formation of inclusion complex.(Table-I). This may be attributed to the transference of the compound from a more protic environment to a less protic environment with in the cavity of $\beta$ - cyclodextrin. This is further supported by IR data The IR stretching frequencies due to different bonds undergo a downward shift towards low energy and the peaks become broader, weaker and smoother. Such changes in spectral characteristics due to inclusion complex formation may be due to the weak interaction like H-bonding, vanderWaal's forces, hydrophobic interactions etc. between the guest compound and the host $\beta$ - cyclodextrin ${ }^{16-17}$.

The phase solubility plots of the compounds in $\beta$ - cyclodextrin solution are shown in Figure 1. In all the cases, it is seen that there is a linear increase in solubility of these compounds with increasing concentration of $\beta$ - cyclodextrin. Since the slopes of all the plots are less than unity the stochiometry of these complexes may be $1: 1^{18}$.

The thermodynamic stability constants $\left(\mathrm{K}_{\mathrm{T}}\right)$ of inclusion complexes were determined by using Benesi-Hilderband relation.

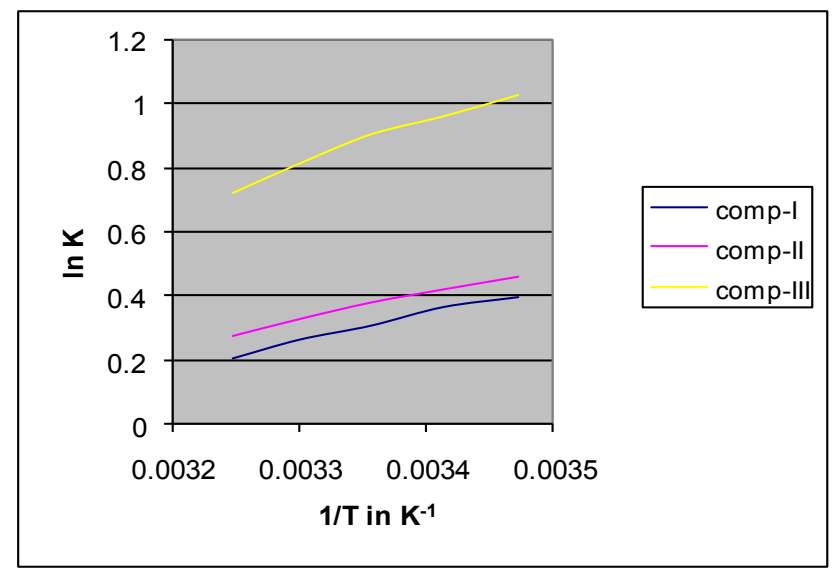

Figure 3: Plot of $\ln \mathrm{K}$ vs. 1/T of Compound I, II and III. 


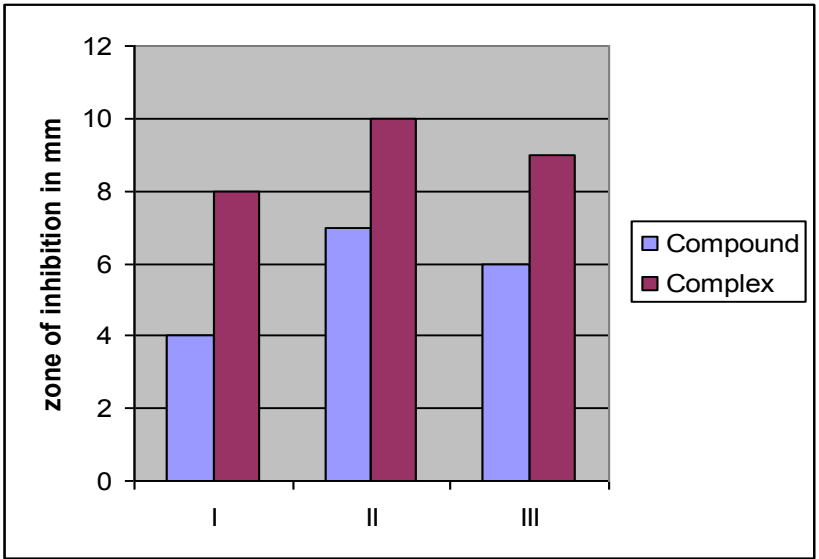

Figure 4A: Antimicrobial susceptibility test of Compound I, II and III against S.aureus.

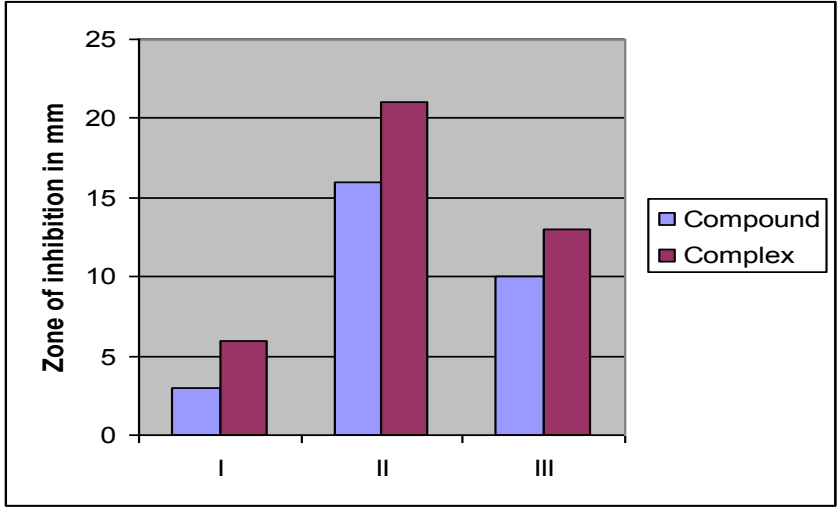

Figure 4B: Antimicrobial susceptibility test of Compound I, II and III against E.coli.

The values of $\mathrm{K}_{\mathrm{T}}$ for all the complexes were calculated using the relation

$$
\mathrm{K}_{\mathrm{T}}=\text { Intercept/Slope. }
$$

The $\mathrm{K}_{\mathrm{T}}$ values of the inclusion complexes of compounds I,II and III with $\beta$ - cyclodextrin are found to be $420.9,231.3,190.78 \mathrm{M}^{-1}$ respectively (Table-2) The data obtained are within 100 to $1000 \mathrm{M}^{-1}$ (ideal values) indicating appreciable stabilities for the inclusion complexes ${ }^{19}$.

Table 2: Thermodynamic data of inclusion complexes at $298 \mathrm{~K}$.

Compound-I : Benzylidenamino-1,3,4-thiadiazino[6,5b]indole.

Compound-II : 2-[2- Hydroxy Benzylidenamino]-1,3,4-thiadiazino[6,5b]indole.

Compound-III : 2-[2--Chloro Benzylidenamino]-1,3,4-thiadiazino[6,5b]indole.

\begin{tabular}{|l|l|l|l|l|}
\hline Complexes & $\mathrm{K}\left(\mathrm{M}^{-1}\right)$ & $\Delta \mathrm{G}(\mathrm{kJ} / \mathrm{MOLE})$ & $\Delta \mathrm{H}(\mathrm{kJ} / \mathrm{MOLE})$ & $\Delta \mathrm{S}(\mathrm{kJ} / \mathrm{MOLE})$ \\
\hline Compound-I- $\beta-\mathrm{CD}$ & 420.9 & -14.98 & -12.105 & 0.00965 \\
\hline Compound-II- $\beta$ - CD & 231.3 & -13.489 & -11.429 & 0.0105 \\
\hline Compound-III- $\beta$ - CD & 190.78 & -13.012 & -11.429 & .0053 \\
\hline
\end{tabular}




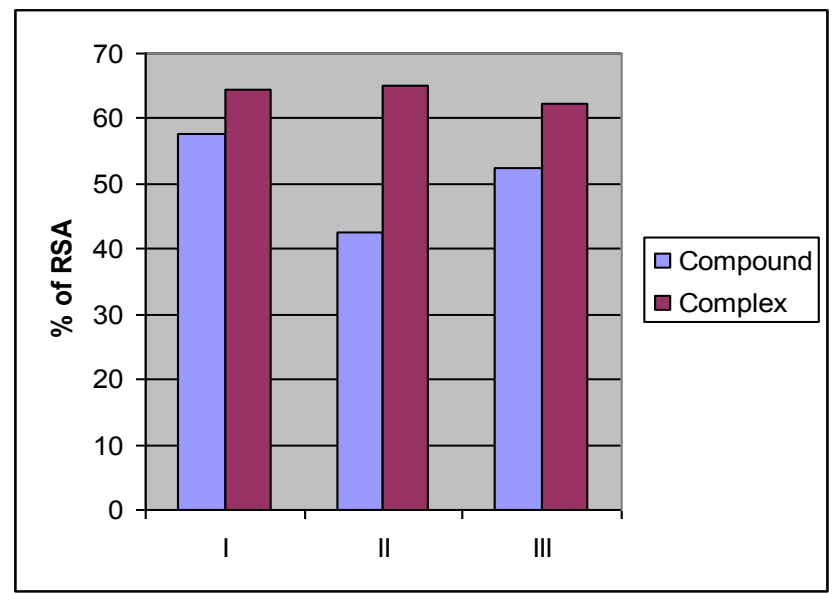

Figure 5: Anti-Oxidant activity of Compound I, II and III.

The thermodynamic parameters associated with the interaction of the compound with $\beta$ cyclodextrin for 1:1 stochiometry have also been calculated by determining stability constant $(\mathrm{K}$ - values) at different temperatures. The $\mathrm{K}$ - values are to found to decrease with rise in temperature as expected for an exothermic process (deencapsulation) ${ }^{20-21}$. The plots of ln $\mathrm{K}$ versus inverse absolute temperature produce linear plots Figure 3. From the slopes of the curves, van't Hoff's reaction isotherm and van'tHoff equation, the values of $\Delta \mathrm{G}$ (change in free energy), $\Delta H$ (change in enthalpy) and $\Delta S$ (change in entropy) have been calculated (Table-2). In Table-2, it is found that $\Delta \mathrm{G}$ values are negative for all the inclusion complexes.

These data clearly demonstrates that formation of inclusion complexes of compounds I, II and III with $\beta$ - cyclodextrin is a spontaneous process. Further it is found that in case of all three inclusion complexes, $\Delta \mathrm{H}$ values are negative (Table-2). The negative value of enthalpy change $(\Delta \mathrm{H})$ indicates that all the three inclusion complex formation is exothermic and energy allowed processes. That is, the compounds are getting stabilized within the cavity of $\beta$ - cyclodextrin by weak intermolecular forces as suggested earlier ${ }^{22-23}$ The antibacterial activities of the compounds and their inclusion complexes against S.aureus and E.coli are shown in fig. 4A and 4B. Both the compounds and their inclusion complexes are susceptible to both the bacteria. However, the inclusion complexes increase the antibacterial activity significantly as compared to their corresponding compounds. This may be attributed to enhanced solubility of the compounds after the inclusion complex formation which becomes more available to specific tissues leading to increased antibacterial activity. ${ }^{25-26}$

The antioxidant activities of the compounds and their inclusion complexes are shown in Fig. 5. The radical scavenging activities of the compounds increase significantly after the formation of inclusion complex. This can be correlated to the higher stability of the compounds due to inclusion complex formation there by increasing the bioaccessibility ${ }^{27}$.

\section{Conclusion}

From the above results and discussion, it is clear that the formation of inclusion complexes of compound-I, II and III is thermodynamically allowed which can be a very good analytical tool for enhancing the bioaccessibility of the drugs. The study further reveals that noncovalent intermolecular forces bind the host $\beta$ - cyclodextrin and guest molecules. The $\Delta \mathrm{G}$, $\Delta \mathrm{S}$ and $\Delta \mathrm{H}$ values support the formation of such complexes. 


\section{Acknowledgement}

The authors thank to Dr. U.L.Narayana, Principal, Indira Gandhi Institute of Pharmaceutical science; Mr. Sanjay Tiwari and Mr. Dilip Kumar Pattnaik for carrying out the IR study. Also the authors are thankful to Dr. J R Panda,Department of Pharmaceutical science, Roland institute of Pharmaceutical Science, Berhampur University for carrying the antimicrobial activity.

\section{References}

1. Sengupta A K., Pandey A. K., Verma H N and Ali Khan M W A, J Ind. Chem Soc, 1985, 62, 165 .

2. Patil R and Biradar J S, Indian J pharma Sci, 2001, 63(4), 299.

3. Shetty M V, Parimo P and Chopra Y M, Europen J Med Chem Chin Ther, 1978, 581

4. Inlon H, Vogelaer H De, Descamps M, Bauthier J, Colot M, Richard J and Charlier R, Chem Abstr, 1978, 88, 601.

5. Oimoni M, Hamada M and Hava T, J Antibiot, 1974, 27, 989.

6. Holla B S and Udupa K V, J Ind Chem Soc, 1988, 65(7), 524.

7. Kapimoto S and Nishie J, Japanese Journal of Tuberculosis, 1954, 2 , 334.

8. Panwar H, Verma R S, Srivastava V K and Ashok Kumar, Indian Journal of Chemistry, 2006, 45B, 2099.

9. Pose-Vilarnovo B, Predomo-Lopez I and Echezarreta-Lopez M, J Pharma Sci, 2001, 13(3), 325.

10. Belikov V.G.and.Komapantseva E V, Khim-Farm Zh, 1990, 24(7), 19.

11. Yano H, Hiramaya F and Arima H, J. Pharma. Sci., 2001, 90(4), 493.

12. Allen C.F.H and Mekee G.H.W,Indole Organic Synthesis, Coll., 1999, 2, 15.

13. Higuchi T and Connors K A., Adv. Anal. Chem. Instrum, 1965, 4, 117.

14.Panda S and Nayak S S, Asian J.Res. Chem, 2009, 2(4), 539.

15. Benesi H.A and Hilderband J.H, J.Am. Chem.Soc., 1999, 71, 2703.

16. Mohammed K.G and Moji C.A., Pharm. Dev. Tech., 2001, 6 , 315.

17. Chen Q and Guowang. D, Chem. J.I., 2001, 6(5), 37.

18. Mukna A.P.and Nagarsenkar M.S, AAPS Phar Sci. Tech., 2001, 5(1), 19.

19. Szetli Z, Molecular entrapment and release properties of drugs by cyclodextrins, Controlled Drug Bio-availibility, Willey Interscience publications, 1985, 3,365.

20. Tommasini S, Raneri S,.Ficarra R,.Calabro M.L and Stancanelli R, J. Pharm.Biomed. Anal., 2004, 35, 379.

21. Rajewski R.A and Stella V.J.,J. Pharm. Sci., 1996, 85, 1142.

22.Loukas Y.L, Vraka V. and Gregordias. G, . J. Pharm.Biomed. Anal., 1997,16, 263.

23. Stalin T, Vasantharani P, Shanti B, Sekhar A.and Rajendra N, Ind J.. Chem, Sec A, 2006, 45, 1113.

24. Astakhova A.V. and.Demina N.B, Pharm. Chem. J., 2004, 38(2), 105.

25. Cruickshank R., Marmion J P and Swain R H A, Medicinal microbiology, 1975,11,91.

26. Astakhova A.V. and.Demina N.B, Pharm. Chem. J., 2004,38(2), 105.

27. Tagashira M and Ohtake Y, Planta Medicinal Journal,64, 555-558(1998). 


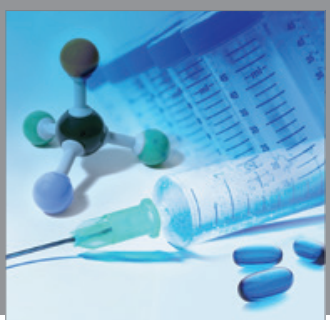

International Journal of

Medicinal Chemistry

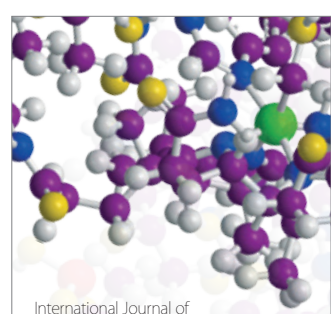

Carbohydrate Chemistry

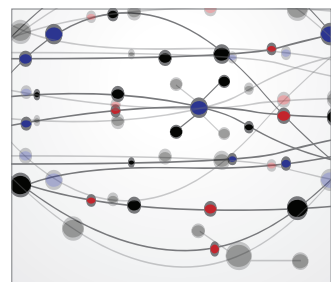

The Scientific World Journal
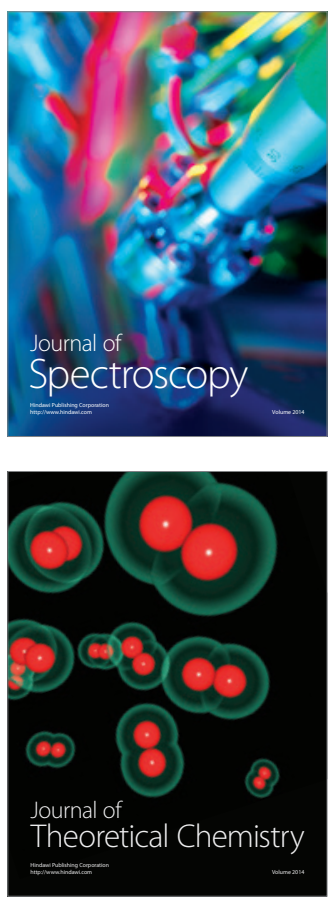
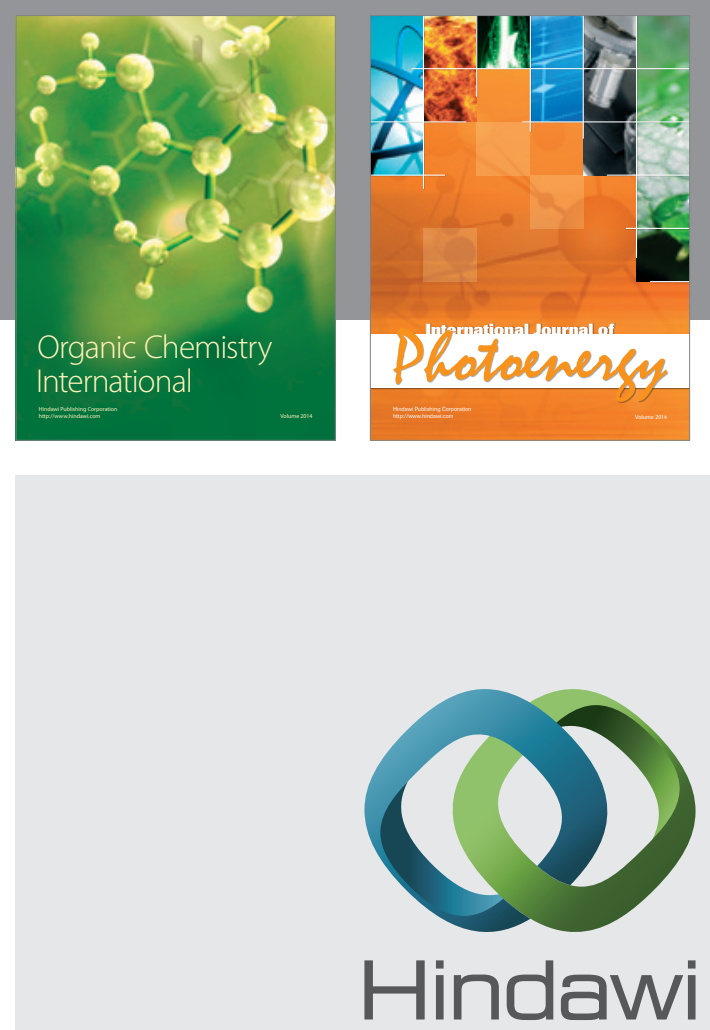

Submit your manuscripts at

http://www.hindawi.com
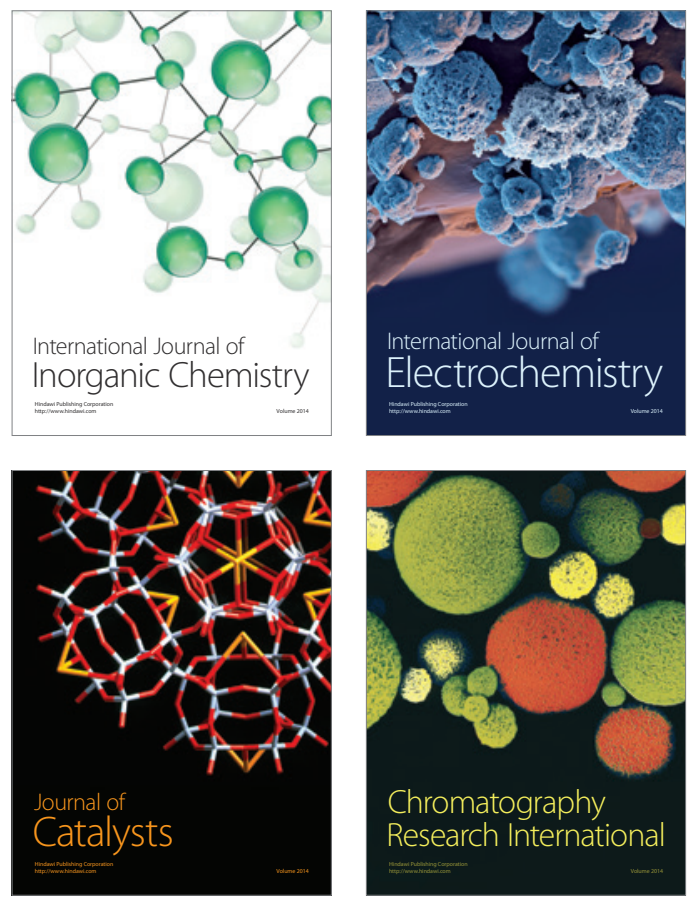
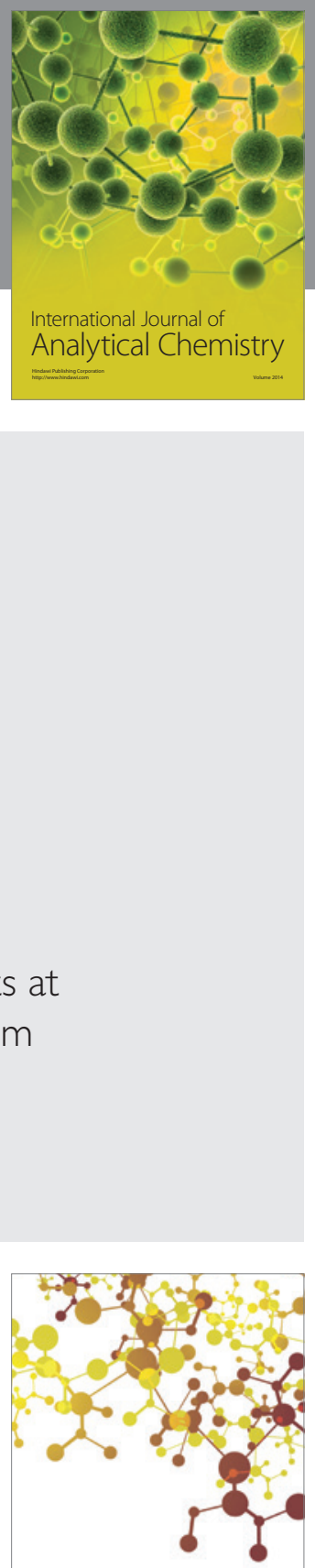

Journal of

Applied Chemistry
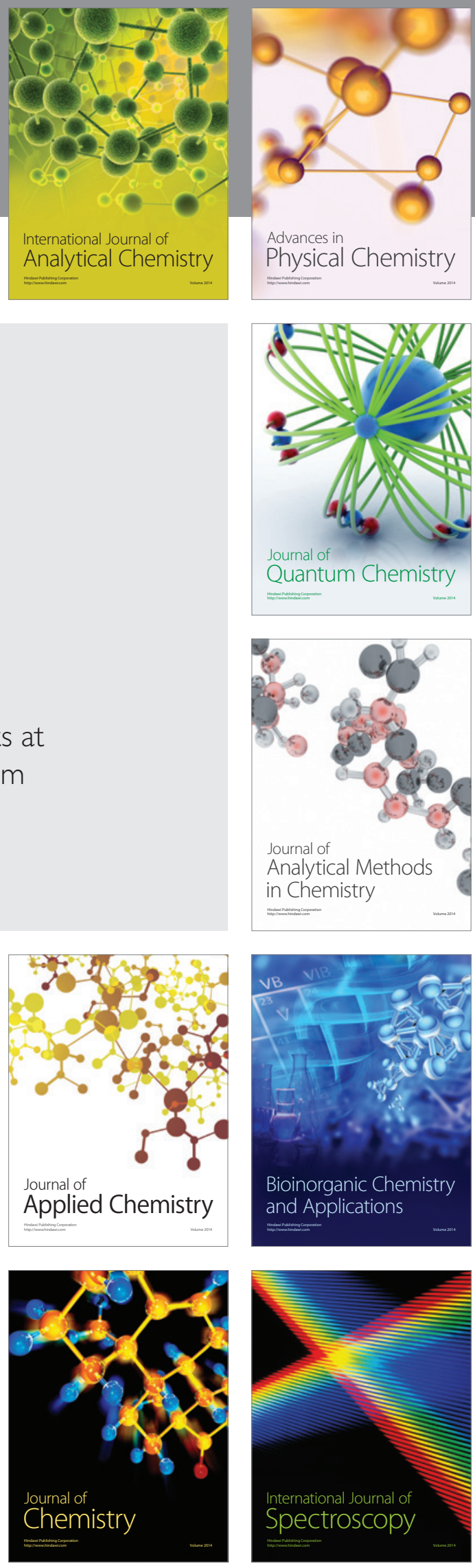